\title{
COMMON CUCKOOS (CUCULUS CANORUS) DO NOT RELY ON INDICATORS OF PARENTAL ABILITIES WHEN SEARCHING FOR HOST NESTS: THE IMPORTANCE OF HOST DEFENSES
}

\author{
Jesús M. Avilés, ${ }^{1,2,6}$ Csaba Moskát, ${ }^{3}$ Miklós Bán, ${ }^{4}$ Rita Hargital, ${ }^{5,7}$ and Deseada ParejO ${ }^{2}$ \\ ${ }^{1}$ Department of Animal Biology, University of Granada, Granada E-18071, Spain; \\ ${ }^{2}$ Arid Zones Research Station, Spanish National Council for Research, Almería E-04001, Spain; \\ ${ }^{3}$ Animal Ecology Research Group, Hungarian Academy of Sciences, Budapest H-1088, Hungary; \\ ${ }^{4}$ Behavioral Ecology Research Group, University of Debrecen, Debrecen H-4032, Hungary; and \\ ${ }^{5}$ Behavioral Ecology Group, Eötvös Loránd University, Budapest H-1053, Hungary
}

\begin{abstract}
Aвstract.-There is widespread evidence that individuals within and among host populations are not evenly parasitized by Common Cuckoos (Cuculus canorus). We first investigated whether the song and nest size of a host species, the Great Reed Warbler (Acrocephalus arundinaceus), reveal information on parental abilities and level of defense against Common Cuckoos. Second, we analyzed whether female Common Cuckoos' preference for host nests is predicted by the degree of song expression and the nest size of the host. Earlier-breeding hosts built bigger nests, were more active singers, and had less rich syllable repertoires than late breeders. Host nestlings raised in a big nest received more feedings than those raised in a small nest. Host males that were active singers were paired with females that built bigger nests. All host pairs rejected nonmimetic artificial eggs, but those with a big nest were more prone to reject natural Common Cuckoo eggs. Thus, Great Reed Warbler pairs with a big nest were more willing to feed nestlings, but also had higher discriminatory abilities against Common Cuckoo eggs, than those with a small nest. These findings, and female Common Cuckoos' inability to capture the information provided by Great Reed Warblers' sexual signals, may explain why the females followed a simple rule of selecting the more visible host nests in the population. Received 26 August 2008, accepted 8 January 2009.
\end{abstract}

Key words: Acrocephalus arundinaceus, brood parasitism, Common Cuckoo, Cuculus canorus, Great Reed Warbler, heterospecific eavesdropping, host quality selection, nest size, parental care, sexual signals.

\section{Cuculus canorus no se Basa en Indicadores de las Habilidades Parentales Cuando Busca Nidos de Hospederos: la Importancia de las Defensas del Hospedero}

ReSUMEN.-Existe abundante evidencia de que los individuos dentro y entre poblaciones hospederas no son parasitados de manera uniforme por Cuculus canorus. Primero, investigamos si el canto y el tamaño del nido de una especie hospedera, Acrocephalus arundinaceus, otorga información sobre las habilidades parentales y el nivel de defensa en contra de C. canorus. Segundo, analizamos si la preferencia de las hembras de C. canorus por los nidos hospederos es predicha por el grado de expresión del canto y el tamaño del nido del hospedero. Los hospederos que criaron más temprano construyeron nidos más grandes, fueron cantantes más activos y presentaron repertorios menos ricos en sílabas que los individuos que criaron más tarde. Los pichones de los hospederos criados en nidos grandes recibieron más alimento que aquellos criados en nidos pequeños. Los machos hospederos que fueron cantantes activos se aparearon con las hembras que construyeron nidos más grandes. Todas las parejas de hospederos rechazaron los huevos artificiales no miméticos, pero aquellas con nidos grandes fueron más propensas a rechazar los huevos naturales de C. canorus. Así, las parejas de A. arundinaceus con nidos grandes estuvieron más dispuestas a alimentar a los pichones de C. canorus, pero también presentaron mayores habilidades para discriminar sus huevos, que aquellas parejas con nidos pequeños. Estos resultados, y la incapacidad de la hembra de C. canorus de captar la información suministrada por las señales sexuales de $A$. arundinaceus, pueden explicar por qué las hembras siguieron una regla simple de seleccionar los nidos hospederos más visibles de la población.

${ }^{6}$ E-mail: javiles@eeza.csic.es

${ }^{7}$ Present address: Institute of Environmental Sciences, College of Nyíregyháza, Nyíregyháza H-4400, Hungary.

The Auk, Vol. 126, Number 2, pages 431-438. ISSN 0004-8038, electronic ISSN 1938-4254. @ 2009 by The American Ornithologists' Union. All rights reserved. Please direct all requests for permission to photocopy or reproduce article content through the University of California Press's Rights and Permissions website, http://www.ucpressjournals. com/reprintInfo.asp. DOI: 10.1525/auk.2009.08162 
ANIMAL COMMUNICATION USUALLY occurs in a network of several signalers and receivers in which unintended receivers ("eavesdroppers"; sensu McGregor and Dabelsteen 1996, McGregor 2005) may process and profit from the information transmitted by signalers (e.g., Grim 2008, Welbergen and Davies 2008). Recently, it has been suggested that the interactions between obligate avian brood parasites and their hosts may represent a particular case of heterospecific eavesdropping on sexually selected signals that reveal the host's parental qualities (Soler et al. 1995, Parejo and Avilés 2007). Obligate avian brood parasites always lay their eggs in the nests of other species that rear their offspring (Davies 2000). Therefore, by eavesdropping on hosts' sexual signals revealing parental qualities or territory quality, obligate brood parasites may obtain information about the prospective survival of their own offspring.

There is widespread evidence that individuals within and among host populations are not evenly parasitized by cuckoos (Krüger 2007). A few studies have previously analyzed the role of hosts' songs in determining the probability of parasitism by Brown-Headed Cowbirds (Molothrus ater) from a location perspective (i.e., higher song activity increases the probability of nest detection by brood parasites; e.g., Clotfelter 1998, Banks and Martin 2001, Grieef and Sealy 2000, Garamszegi and Avilés 2005). Also, Soler et al. (1995) found that female Great Spotted Cuckoos (Clamator glandarius) in Spain were more prone to parasitize large European Magpie (Pica pica) nests, where viability of the parasite offspring was high (but see McLaren and Sealy 2003). No attempt has been made to assess the role of hosts' sexual signals in determining the probability of parasitism by Common Cuckoos (Cuculus canorus; hereafter "cuckoos"), despite the fact that this is a very well-known system (Davies 2000).

Great Reed Warblers (Acrocephalus arundinaceus) are the most common hosts of cuckoos on the plains of Hungary. Like many other cuckoo hosts, Great Reed Warblers reject many, but not all, cuckoo eggs (Moskát and Honza 2002). Previous studies in the region demonstrated that female cuckoos preferred Great Reed Warbler nests that were near vantage points, more visible as judged by humans, or both (Moskát and Honza 2000). Further, evidence suggests that female cuckoos have evolved finely tuned discriminatory capacities, given that they prefer to parasitize host nests that contain eggs similar in appearance to their own eggs, which hinders the host's discriminatory task (Avilés et al. 2006, Cherry et al. 2007). These studies, however, have neglected the possibility that cuckoos use the sexual signals of Great Reed Warblers as cues, which may have biased the results if the hosts were not evenly distributed, within a population, in relation to their sexual signals.

Male Great Reed Warblers sing highly conspicuous songs, which are subject to a directional female mating preference (e.g., Catchpole et al. 1985, 1986; Catchpole 1986; Hasselquist 1998; Forstmeier and Leisler 2004). More importantly, from our perspective, Hasselquist et al. (1996) found a positive relationship between the viability of the offspring and the repertoire size of the genetic father. Male Great Reed Warblers' songs, therefore, may reveal aspects of offspring viability that could be of interest to eavesdropping cuckoos. In the same vein, once pairing has occurred, female Great Reed Warblers build their nests without the male's help (Cramp 1998). Nest size (Soler et al. 1998, 2001; De Neve et al. 2004; Szentirmai et al. 2005) and nest-building activities (Soler et al. 1995, Palomino et al. 1998, Szentirmai et al. 2005) have been shown to be postpairing signals that reveal parental quality in European Magpies and other passerine birds (e.g., Soler et al. 1998, Szentirmai et al. 2005). Thus, the nest-building behavior of female Great Reed Warblers, as estimated from nest size, may be related to a willingness to invest in parental care and, thus, may also indirectly assist eavesdropping brood parasites in assessing some aspects of their offspring viability (see also McClaren and Sealy 2003).

We examined the natural variation present in two potential species-specific signals, song and nest size, as well as their information content in terms of parental quality and level of defense against cuckoos in a Great Reed Warbler population heavily parasitized by cuckoos. Second, we analyzed whether female cuckoos' preference for host nests is predicted by the song characteristics and the size of the hosts' nests. We expected that the responses of eavesdropping cuckoos to the signal variation in our host population would depend on parental qualities expressed by the sexual signals of hosts. From a cuckoo's point of view, the suitability of a host may depend on how prone it is to reject cuckoo eggs and its ability to raise parasitic chicks (Davies 2000, Grim et al. 2003, Grim 2007). Therefore, if host song and nest size, as sexual signals, simultaneously reflect the host's ability to raise a chick and its ability to recognize and reject cuckoo eggs, cuckoos may disregard these signals when searching for nests. However, we would expect that cuckoos' selection of host nests is not random, with respect to the signal variation we found in our study population, if signals reflect either the host's ability to raise a chick or its inability to discriminate against cuckoo eggs.

\section{Methods}

Study area.-Field work was conducted around the village of Apaj, Hungary $\left(47^{\circ} 07^{\prime} \mathrm{N}, 19^{\circ} 06^{\prime} \mathrm{E}\right)$, in 2006 . Great Reed Warblers breed in reed beds along small channels and are parasitized at unusually high frequencies ( 65\%) by cuckoos (Moskát and Honza 2002). For a detailed description of the study area, see Moskát and Honza (2000). Great Reed Warblers typically arrive at our study area in early May and start breeding in mid-May. From 10 May, we systematically checked the reed beds for nests at least twice a week. Most of the nests were found in the nest-building or early egglaying stages, which allowed us to monitor the fate of natural cuckoo parasitism in our population (Moskát and Honza 2002). Each nest was checked daily, and all Great Reed Warbler and cuckoo eggs were marked with waterproof pens. As in previous studies, parasitized nests that escaped predation for six days after parasitism were assessed as acceptors or rejectors (egg ejection or nest desertion; Moskát and Honza 2002, Hauber et al. 2006). The inclusion of nest desertion as a form of rejection is justified for this particular system, given that it can affect $15-19 \%$ of naturally parasitized nests in Apaj (Bártol et al. 2002, Moskát and Honza 2002), which is almost triple the desertion rate for nonparasitized nests (Bártol et al. 2002).

We also artificially parasitized a randomly selected portion of unparasitized nests in our population to study the relationship 
between hosts' discriminatory abilities and the degree of speciesspecific signaling. Female cuckoos often remove a host egg when laying their own egg (Wyllie 1981), so we simulated parasitism by maintaining the existing clutch size in each artificially parasitized nest. We experimentally parasitized clutches with nonmimetic ( $n=14$ nests) and mimetic eggs ( $n=9$ nests). In the parasitized nonmimetic group of nests, we manipulated one egg in each clutch by dying its entire shell with a transparent yellow highlighter pen (Swan Stabilo Boss art no. 70/24). In addition, we added 12 brown spots with a felt pen (Faber-Castel OHP-Plus 1525 permanent, color code 78). Cuckoo eggs of a yellowish color occur in our study population, though rarely. Therefore, although cuckoo eggs are similar in size to Great Reed Warbler eggs (Török et al. 2004), the use of the term "nonmimetic" is justified in this case of artificial parasitism (see fig. 1 in Moskát et al. 2008a). In the parasitized "mimetic" group of nests, one host egg was manipulated by adding 12 brown spots with a felt pen (Faber-Castel OHP-Plus 1525 permanent, color code 78 ). The spots were $\sim 4 \mathrm{~mm}$ in diameter and corresponded to the maximum size of natural spots on Great Reed Warbler eggs. These spots allowed the egg's background color to be visible, and previous studies in our population have shown that most are accepted by Great Reed Warblers (Hauber et al. 2006, Moskát et al. 2008b), thus justifying the use of the term "mimetic." To simulate natural parasitism (Moskát and Honza 2002), we applied both treatments during egg laying, usually after the fourth egg had been laid (rarely after the third or fifth egg). We monitored nests for six consecutive days after manipulation and report two types of host responses: acceptance or rejection of the parasitic egg (no desertion occurred). Only clutches not parasitized by a cuckoo and not depredated during the experimental period were used for these analyses.

Song recordings.-Male Great Reed Warblers have two different types of songs, which greatly differ in length. Unmated individuals produce long songs that consist of a wide variety of high-amplitude elements, and they switch to short songs that consist of low-amplitude syllables once they have a fertilizable, nestbuilding (or egg-laying) female to guard (Hasselquist and Bensch 1991). Playback experiments in the field and in the laboratory have demonstrated that long songs are attractive to females (Catchpole 1983, 1986), so eavesdropping cuckoos could target long Great Reed Warbler songs for future brood parasitism. We recorded males that sang a minimum of 30 consecutive strophes of long songs, which is sufficient to determine repertoire size in this species (Forstmeier et al. 2006). Recordings were made between 0500 and 1000 hours with a Marantz PMD670 recorder and a K6ME66 Sennheiser directional microphone and were analyzed with RAVEN, version 1.2 (Cornell Lab of Ornithology, Ithaca, New York). Five of the 22 sampled males were color-ringed before we recorded their songs. Continuous monitoring allowed us to confirm that these five males remained within their territories throughout the breeding season.

To characterize songs, we extracted five parameters from each of the 120 records belonging to the 22 males: (1) song rate, calculated as the proportion of time that a bird was singing as a function of record duration; (2) repertoire size, or the number of different syllable types found in all the strophes of a record (to ensure consistency in classification, all syllables were categorized by the same person [M.B.] on the basis of visual inspection of spectrograms); (3) strophe length, the average length of all the strophes in a record; (4) percentage performance time (PPT), the average ratio of strophe length divided by the sum of strophe lengths and the subsequent silent period (Forstmeier et al. 2006); and (5) syllable switches, the average number of syllable-type switches within a strophe.

Nest volume.-A nest-volume index was estimated by multiplying nest height $(\mathrm{cm})$, maximum nest width $(\mathrm{cm})$, and minimum nest width (cm) (Moskát and Honza 2000). To ensure consistency, measurements were always taken by the same person (M.B.) while the nests were active. In addition, the number of reed stems to which the nests were attached was recorded. The average number of harnessed stems per nest was 5 (range: $2-11$ ). Larger nests contained more reed stems $(r=0.26, F=5.12, \mathrm{df}=1$ and $67, P=0.02$, $n=69$ nests), which supports the assumption that nest volume is a good correlate of building effort in Great Reed Warblers.

Parental care.-The rate of nestling provisioning by parents was recorded with two fully compatible digital video cameras (Canon MV500i and 550i with Fuji DX 60-min cassettes) at 18 randomly selected unparasitized nests. This figure represents nearly $50 \%$ of the unparasitized nests in our population in which nestling Great Reed Warblers reached five days of age. The cameras were attached to tripods placed in reeds approximately $3-4 \mathrm{~m}$ from nests, to record parental feeding. We left cameras for $15 \mathrm{~min}$ before recordings started to habituate the birds to their presence. We used provisioning rate (number of feeding visits hour ${ }^{-1}$, calculated from $1 \mathrm{~h}$ of observation nest ${ }^{-1}$ ) when nestlings were about five days old (nestling age at the observation: average $\pm \mathrm{SD}=5.55 \pm$ 0.92 days) as a measure of parental care.

Distance to vantage points and nest visibility.-A previous study of the same population showed that Great Reed Warbler nests that are close to cuckoos' vantage points and more visible to researchers were more likely to be parasitized by cuckoos (Moskát and Honza 2000). Therefore, we estimated distance (m) to vantage points for every nest with a Garmin 60 geographic positioning system. We defined this as the distance from the nest to the closest tree or electric wire on which a cuckoo could land. Following Moskát and Honza (2000), we evaluated nest visibility from four points (north, east, south, and west) at a distance of $3 \mathrm{~m}$, using a scale of 1-5: (1) bad-the nest is difficult to see from all directions, even from closer than $3 \mathrm{~m}$; (2) intermediate1 (between the states of bad and moderate) - the nest is difficult to see from $3 \mathrm{~m}$, but from a closer distance it can easily be seen, at least from one direction; (3) moderate - the nest can be seen from $3 \mathrm{~m}$ in one direction, and from a closer distance it can easily be recognized; (4) intermediate2 (between the states of moderate and good) - the nest is seen relatively well from $3 \mathrm{~m}$, and from a greater distance in one direction; and (5) good-the nest is seen very well from $3 \mathrm{~m}$, and from a greater distance in more than one direction (Moskát and Honza 2000).

Statistical analyses.-Song variables were interrelated, so we performed a principal component analysis (PCA) on the five variables to reduce the number of correlated variables into a single variable summarizing song variation. The first component explained $68.0 \%$ of the total variance in song and had high positive loading for song rate $(0.89)$ and negative loadings for repertoire size $(-0.76)$, strophe length $(-0.58)$, PPT $(-0.93)$, and syllable switches $(-0.90)$. Hence, males with high positive scores for this 
first component were more active singers, though their syllable repertoires were less rich.

The data complied with normality assumptions, and general linear models (GLM procedure in SAS; SAS Institute 1996) with normal error distribution were used to explore the relationships between likely sexual signals (i.e., nest volume and PC scores on song traits) and parental quality (i.e., provisioning rate). Provisioning rate may be affected by laying date and number of nestlings, given that laying date is an age-dependent feature in Great Reed Warblers (Lotem et al. 1992), and larger numbers of nestlings require higher provisioning rates. Thus, laying date and brood size were entered in the model to control for possible biases.

We used logistic regression models (GENMOD procedure in SAS) for testing the relationship between the fate of natural and artificial cuckoo parasitism in a nest (dependent variable: acceptance vs. rejection) and the expression of sexual signals of the nest owners. We entered laying date as a covariate, because young female Great Reed Warblers often lay in the middle of the breeding season and parasitic egg-recognition abilities are assumed to increase with age (Lotem et al. 1992). We also entered the kind of artificial egg (mimetic vs. nonmimetic) in the model as a fixed factor when dealing with rejection of artificial cuckoo eggs, because nonmimetic eggs are likely to be removed by cuckoo hosts (Davies 2000). Finally, we used a multiple logistic regression model with probability of parasitism as a binomial dependent variable (parasitized vs. nonparasitized) and variables related to sexual signals, and laying date, as independent variables. Nest visibility and perch distance were also entered in the models, because previous work has shown that they are determining factors in predicting the probability of cuckoo parasitism in our population (Moskát and Honza 2000). Finally, to account for the possibility that nest crypsis was a sexually selected trait in Great Reed Warblers, we used Pearson correlations to check for relationships between nest visibility and laying date and number of feedings.

Model selection was performed by removing, one by one, the effects that were farthest from statistical significance. Because of low sample size, we did not test interactive effects between independent variables.

\section{Results}

\section{Expression of Potential Sexual Signals and Parental Quality in Great Reed Warblers}

Nest volume.-In our study population, Great Reed Warblers built nests $(n=116)$ with an average $( \pm$ SD) volume of $972.83 \pm$ $224.13 \mathrm{~cm}^{3}$. Variation in volume between nests was perceptible: the smallest nest found was about a third the volume of the biggest one (range: $448-1,700 \mathrm{~cm}^{3}$ ). Early breeders produced nests with larger volume than late breeders $(r=-0.38, F=13.02, \mathrm{df}=1$ and $77, P=0.0005$; Fig. 1 ). Video recordings revealed that variation in the rate of nestling provisioning by adult Great Reed Warblers was marginally explained by nest size (volume effect: $r=0.43, F=$ $3.80, \mathrm{df}=1$ and $16, P=0.06$; Fig. 2 ), but not by laying date (layingdate effect: $F=0.51, \mathrm{df}=1$ and $15, P=0.48$ ) or the number of fledglings at the nests (number-of-fledglings effect: $F=0.21, \mathrm{df}=1$ and $14, P=0.65)$.

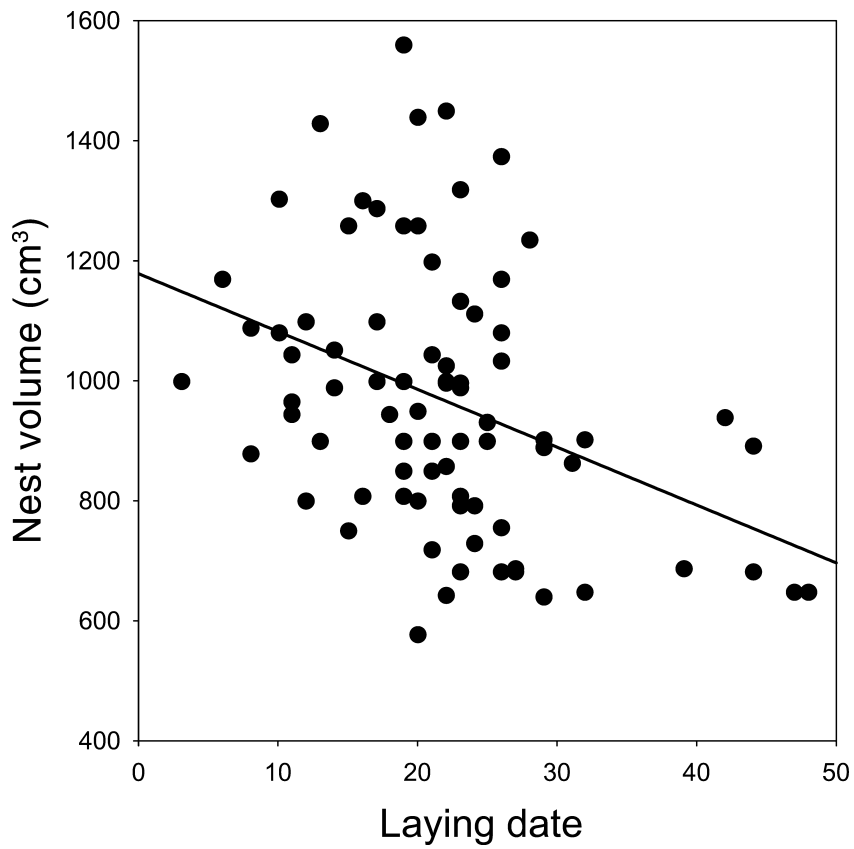

FIG. 1. Relation between nest volume and laying date ( $1=1$ May $)$ in Great Reed Warblers ( $n=79$ nests).

Song.-Early breeders were marginally significantly more active singers and had smaller syllable repertoires (i.e., higher PC1 scores) than late breeders in Apaj (Spearman correlation: $r_{\mathrm{s}}=$ $-0.40, P=0.06, n=21$; Fig. 3). Unfortunately, we were able to videotape only three nests in which male songs had been recorded,

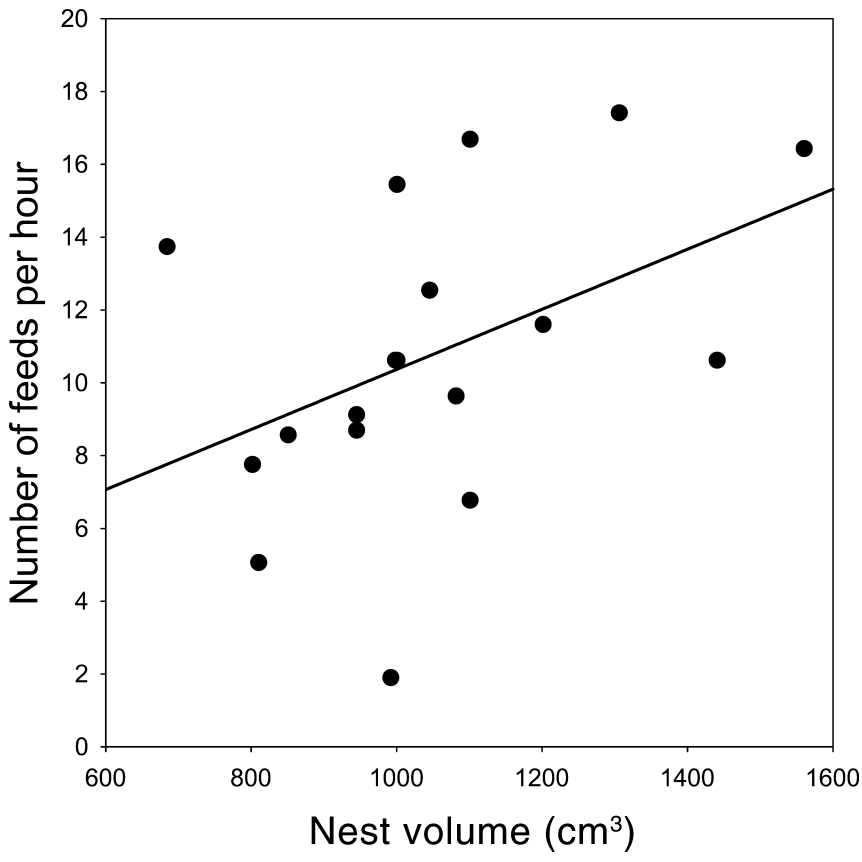

FIG. 2. Relation between number of feedings in $1 \mathrm{~h}$ and nest volume in Great Reed Warblers ( $n=18$ nests). 


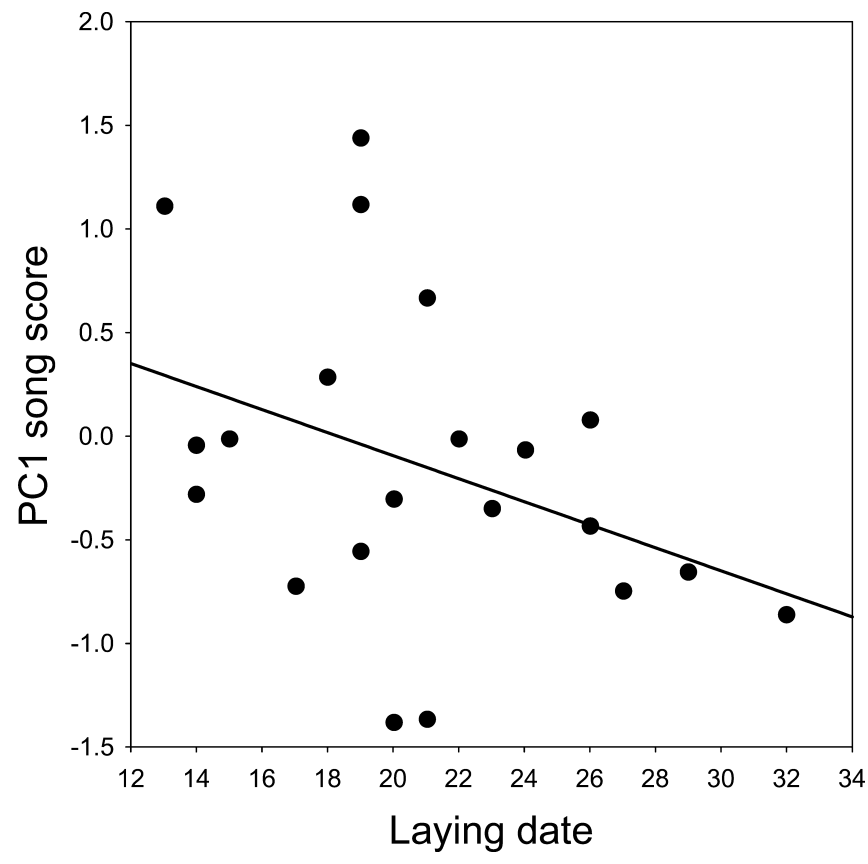

FIG. 3. Relation between song scores and laying date ( $1=1$ May) in Great Reed Warblers ( $n=21$ nests).

which precluded a direct test of male song as an indicator of parental quality at the nests. However, characteristics of male songs were related to nest volume (Spearman correlation: $r_{\mathrm{s}}=0.42, P=$ $0.04, n=22$ ). Active male singers (i.e., those with high PC1 scores) were mated with females that built nests of larger volume (Fig. 4).

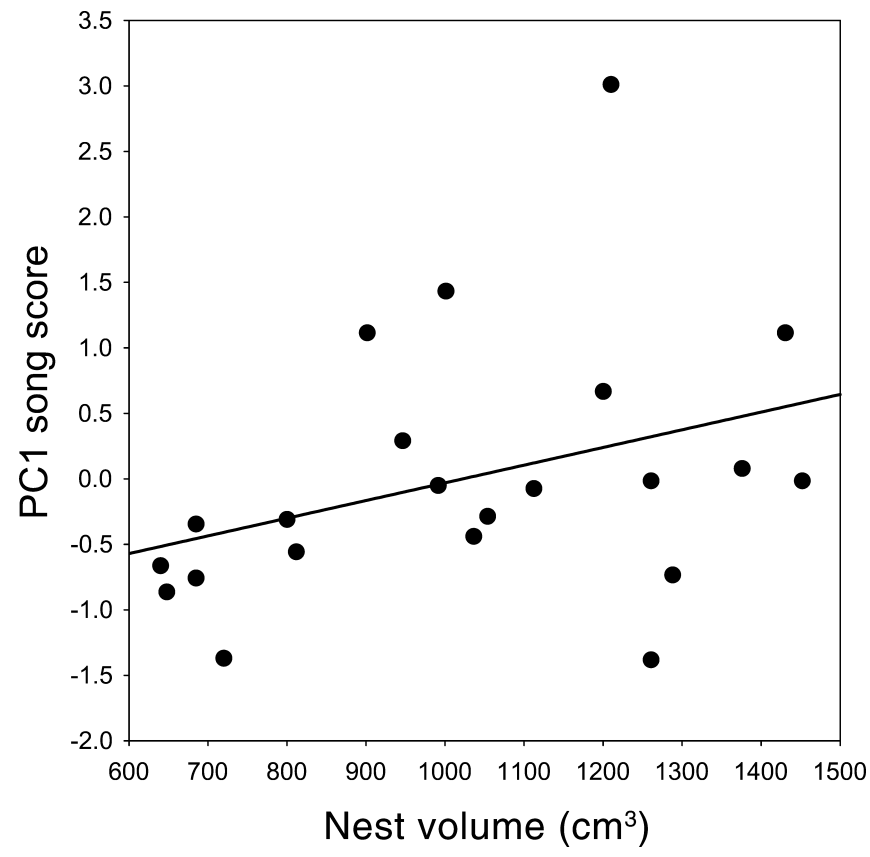

FIG. 4. Relation between song scores and nest volume in Great Reed Warblers ( $n=22$ nests).

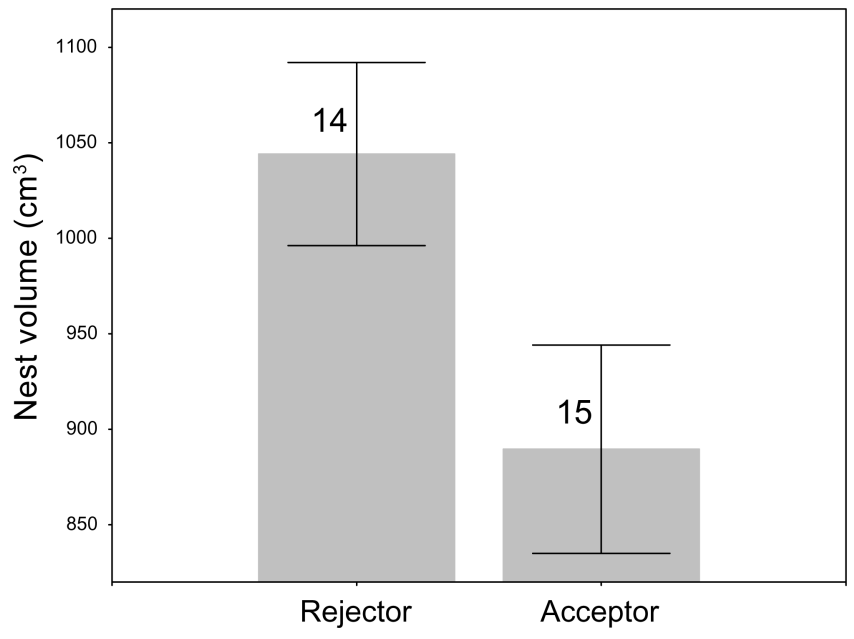

FIG. 5. Volume (means \pm SE) of Great Reed Warbler nests in relation to the occurrence of rejection of natural Common Cuckoo eggs. Sample sizes are on mean bars.

This association was likely mediated by laying date, because nest volume and $\mathrm{PC} 1$ scores were unrelated when laying date was considered in the analysis (volume effect: $F=0.82, \mathrm{df}=1$ and $18, P=$ 0.37 ; laying-date effect: $F=1.36, \mathrm{df}=1$ and $18, P=0.25$ ).

\section{Expression of Potential Sexual Signals and Level of Defense against Cuckoos}

Thirty-eight of the 60 Great Reed Warbler nests found during the nest-building stage were parasitized by cuckoos (parasitism frequency $=63.3 \%$ ). We could not ascertain the fate of cuckoo eggs in eight nests because they were depredated promptly after being parasitized. Great Reed Warblers rejected at least one cuckoo egg in 14 of the remaining 30 nests (rejection rate of natural cuckoo eggs $=46.7 \%)$.

Interestingly, rejection of natural cuckoo eggs was related to nest size (volume effect: $\chi^{2}=4.39, \mathrm{df}=1, P=0.03$ ) once we controlled for the effect of laying date (laying-date effect: $\chi^{2}=3.61, \mathrm{df}=1$, $P=0.057)$. Pairs with a big nest were more prone to reject natural cuckoo eggs than those with a small nest (Fig. 5). The probability of rejection of natural cuckoo eggs, however, was unrelated to song characteristics (song effect: $\chi^{2}=0.09, \mathrm{df}=1, P=0.76$ ).

Nest size, however, did not explain rejection among the artificially parasitized Great Reed Warbler nests (volume effect: $\chi^{2}=1.76, \mathrm{df}=1, P=0.18$ ). Also, laying-date effects on rejection of artificial cuckoo eggs were negligible (laying-date effect: $\chi^{2}=0.60$, $\mathrm{df}=1, P=0.18$ ). Because of low sample size, we could not test for a relationship between song and host response to cuckoo parasitism. Rejection in this group of nests was influenced only by the level of egg mimicry (mimicry effect: $\chi^{2}=14.95, \mathrm{df}=1, P<0.0001$ ), with mimetic eggs (33.3\%) less prone to being rejected than nonmimetic eggs (100\%).

\section{Cuckoo Nest Selection and Host Sexual Signals}

A multivariate analysis in which all factors likely to affect cuckoo parasitism were simultaneously considered revealed that the probability of cuckoo parasitism was unrelated to Great Reed Warbler 
TABLE 1. Results of a logistic regression testing for the effect of Great Reed Warbler song, nest size, perch proximity, laying date, and nest visibility on the probability of parasitism by Common Cuckoos. Independent effects are presented in the order in which they were removed (see text). The number $(n)$ of nests in which measurements were taken for each independent factor is given in parentheses.

\begin{tabular}{lccc}
\hline Source & \multicolumn{1}{c}{ df } & $\chi^{2}$ & $P$ \\
\hline PC1 scores $(n=20$ nests) & 1 and 17 & 0.01 & 0.91 \\
Perch distance $(n=74$ nests) & 1 and 47 & 0.03 & 0.85 \\
Nest volume $(n=70$ nests) & 1 and 48 & 0.11 & 0.73 \\
Laying date $(n=56$ nests) & 1 and 50 & 0.25 & 0.62 \\
Variables retained in the model: & & & \\
$\quad$ Nest visibility $(n=70$ nests) & 1 and 68 & 3.83 & 0.050 \\
\hline
\end{tabular}

song and nest size (Table 1). In addition, laying date and proximity to a perch site did not predict cuckoo parasitism (Table 1). Instead, the probability of cuckoo parasitism was significantly influenced by the visibility of hosts' nests: parasitized nests were more visible (Fig. 6) than unparasitized nests (Table 1). Nest visibility was not significantly correlated with number of feedings $(r=-0.23, P=$ $0.40, n=17)$ or laying date $(r=0.24, P=0.09, n=53)$.

\section{Discussion}

The present study confirms the suggestions of previous investigators that the expression of host signals near host nests might reveal aspects of hosts' parental capacities that are critical for parasitic cuckoos in selecting individuals to parasitize (Soler et al. 1995, Parejo and Avilés 2007). We found that nest size and singing activity of male hosts declined seasonally and that hosts' nestlings raised in larger nests received more feedings than those raised in a small nest, though this result was barely significant $(P=0.06)$. Most active singers in the host population also were mated with females that built bigger nests. A multivariate logistic analysis,

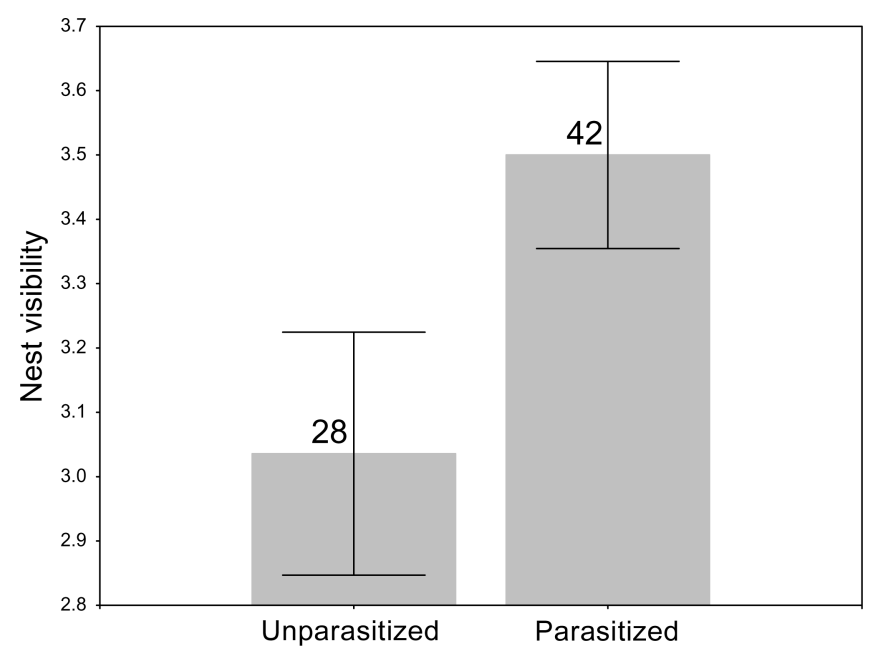

FIG. 6. Nest visibility (means \pm SE) of Great Reed Warbler nests in relation to the occurrence of parasitism by Common Cuckoos. Sample sizes are on mean bars. in which all factors that likely influence the probability of cuckoo parasitism were simultaneously considered, revealed that more visible nests were more prone to be selected by female cuckoos. Neither nest size nor song output-variables that likely reflect the host's parental abilities-predicted the probability of cuckoo parasitism. Thus, our results do not indicate that cuckoos eavesdrop on Great Reed Warblers' sexual signals; rather, female cuckoos may follow a simple rule of parasitizing the most accessible Great Reed Warbler nests in the population.

Early passerine nests are more successful (Perrins 1970). Because most of the Great Reed Warblers in our study population were unmarked, we could not ascertain whether the late breeders that built smaller nests and sang less were young, inexperienced individuals or low-quality adults. In any case, both young, inexperienced and low-quality adult pairs are expected to give parasite offspring less care than experienced, high-quality pairs. Thus, nest size and song outcome could be used by cuckoos as reliable indicators of the rearing capacities of a particular Great Reed Warbler pair. However, if cuckoos parasitize only hosts with elaborate songs, this might result in strong selection against elaborate songs in the host, considering the extremely high frequency of cuckoo parasitism in this area. This would be consistent with the results of a study of cowbird parasitism in which host species had smaller song repertoires than non-host species (Garamszegi and Avilés 2005). Also, it may explain why early-breeding (presumably older) males in the present study had marginally smaller repertoires than late breeders, which contrasts with results from other populations of Great Reed Warblers (e.g., Catchpole et al. 1986, Hasselquist et al. 1996, Forstmeier and Leisler 2004).

Particularly novel is the finding that the expression of sexual signals by individual hosts may reflect discriminatory abilities against parasitism by cuckoos. Indeed, all the Great Reed Warbler pairs we tested rejected the nonmimetic eggs we introduced, but pairs with big nests recognized a cuckoo egg better than those with a small nest. It seems that the informative value of nest size as a predictor of discriminatory abilities is evident only at naturally parasitised nests. This is clearly relevant to understanding cuckoos, which have evolved a moderately good (sometimes "perfect") level of mimicry of Great Reed Warbler eggs in Apaj (Moskát and Honza 2002, Cherry et al. 2007). By relying on Great Reed Warbler nest size, a female cuckoo may obtain information on the probability that her eggs would be evicted from a particular nest. That is, the benefits for a female cuckoo, in terms of parental care, of selecting a big nest are counterbalanced by the costs of egg rejection. The association between rejection of cuckoo eggs and parental abilities may be attributable to these two behavioral traits being agedependent in Great Reed Warblers. Previous studies have shown that discrimination of cuckoo eggs by Great Reed Warblers is an age-dependent behavior (Lotem et al. 1995). Older male Great Reed Warblers also sing more elaborate songs (Hasselquist et al. 1996, Hasselquist 1998; but see Forstmeier et al. 2006) and may have different habitat preferences (Grim 2002). Alternatively, individual Great Reed Warblers may simultaneously exhibit high proficiency in feeding and in avoiding cuckoo parasitism, because these two behavioral tasks are governed by a common cognitive capacity (Sih et al. 2004). Finally, in this population, $>60 \%$ of Great Reed Warbler nests receive at least one cuckoo egg, and multiple parasitism is frequent (Moskát and Honza 2002). Thus, a preference for 
high-quality hosts in this cuckoo population may be "punished" by the exceptionally high frequency of parasitism, which increases the chance that prospecting female cuckoos will find alreadyparasitized nests. Multiple parasitism is especially costly for brood parasites whose chicks evict all eggs and nestmates (Davies 2000).

Female cuckoos parasitized more visible than nonvisible nests in Apaj. It could be argued that host-nest crypsis better predicted an individual's parental quality than its signaling. However, neither laying date nor number of feedings was related to nest visibility in our population. Visible nests probably allow female cuckoos to more effectively inspect a nest before laying and to parasitize the nest more quickly, thus diminishing the risk of being chased by hosts (Wyllie 1981). Also, the high risk of multiple parasitism and the high density of cuckoos in the study population (see above) may have facilitated nest selection based on simple rules. This finding only partially confirms previous findings by Moskát and Honza (2000) in the same population. In that study, perch distance, as well as nest visibility, mainly explained the probability of cuckoo parasitism. Our study was conducted in the same geographic area but, because of habitat degradation, we sampled reed beds situated in channels adjacent to those sampled by Moskát and Honza (2000). In the present study, tree lines followed the channel more continuously than in the earlier study, where trees were more patchily distributed in relation to the reedbed line. Differences in habitat structure between the two studies may explain the difference between the two results regarding the importance of cuckoos' vantage points.

In conclusion, we found that nest size was positively related to the quality of parental care in Great Reed Warblers, as well as to their capacity to reject cuckoo eggs. Therefore, nest size may reveal multiple but contradictory aspects of host suitability, and cuckoos may favor a simple nest-visibility rule when searching for host nests. This may help to explain why we did not find support for the suggestion that cuckoos eavesdrop on the sexual signals of Great Reed Warblers, which is consistent with previous negative results in studies of exploitation of sexual signals by cuckoos. Before stronger inferences can be made, however, this multiplesignaling approach needs to be replicated in a multi-year study that includes other host behaviors that may affect brood parasites, such as those related to the expression of hosts' sexual ornaments.

\section{ACKNOWLEDGMENTS}

P. Laiolo kindly advised us on song recording equipment. M. Soler provided the software for song analysis, and D. Martín-Gálvez taught us to use it. A. M. Dufty, Jr., greatly improved the flow of the text, and two anonymous reviewers made useful suggestions. The study was supported by the Hungarian National Research Fund (OTKA, grant no. T48397 to C.M.) and by a bilateral grant from the Spanish and Hungarian governments (TéT, grant no. E-23/2005 to J.M.A. and C.M.). License to perform this research was provided by the Danube Valley Environmental and Water Authority of the Ministry of Environment and Water in Hungary.

\section{Literature Cited}

Avilés, J. M., B. G. Stokke, A. Moksnes, E. Røskaft, M. Åsmul, AND A. P. MøLLER. 2006. Rapid increase in cuckoo egg matching in a recently parasitized reed warbler population. Journal of Evolutionary Biology 19:1901-1910.

BAnKs, A. J., AND T. E. MARTin. 2001. Host activity and the risk of nest parasitism by Brown-headed Cowbirds. Behavioral Ecology 12:31-40.

Bártol, I., Z. Karcza, C. Moskát, E. Røskaft, and T. KISBENEDEK. 2002. Responses of Great Reed Warblers Acrocephalus arundinaceus to experimental brood parasitism: The effects of a cuckoo Cuculus canorus dummy and egg mimicry. Journal of Avian Biology 33:420-425.

Catchpole, C. K. 1983. Variation in the song of the Great Reed Warbler Acrocephalus arundinaceus in relation to mate attraction and territorial defense. Animal Behaviour 31:1217-1225.

CAtchpole, C. K. 1986. Song repertoires and reproductive success in the Great Reed Warbler Acrocephalus arundinaceus. Behavioral Ecology and Sociobiology 19:439-445.

Catchpole, C. K., B. Leisler, And J. DitTAmi. 1986. Sexual differences in the responses of captive Great Reed Warblers (Acrocephalus arundinaceus) to variation in song structure and repertoire size. Ethology 73:69-77.

Catchpole, C. [K.], B. Leisler, and H. Winkler. 1985. Polygyny in the Great Reed Warbler, Acrocephalus arundinaceus: A possible case of deception. Behavioral Ecology and Sociobiology 16:285-291.

Cherry, M. I., A. T. D. Bennett, And C. Moskát. 2007. Do cuckoos choose nests of Great Reed Warblers on the basis of host egg appearance? Journal of Evolutionary Biology 20:1218-1222.

Clotfelter, E. D. 1998. What cues do Brown-headed Cowbirds use to locate Red-winged Blackbird host nests? Animal Behaviour 55:1181-1189.

Cramp, S. 1998. The Complete Birds of the Western Palearctic. [CD-ROM.] Oxford University Press, Oxford, United Kingdom.

Davies, N. B. 2000. Cuckoos, Cowbirds and Other Cheats. T \& A D Poyser, London.

De Neve, L., J. J. Soler, M. Soler, and T. Pérez-Contreras. 2004. Nest size predicts the effect of food supplementation to magpie nestlings on their immunocompetence: An experimental test of nest size indicating parental ability. Behavioral Ecology 15:1031-1036.

Forstmeier, W., D. Hasselquist, S. Bensch, and B. Leisler. 2006. Does song reflect age and viability? A comparison between two populations of the Great Reed Warbler Acrocephalus arundinaceus. Behavioral Ecology and Sociobiology 59:634-643.

Forstmeier, W., ANd B. Leisler. 2004. Repertoire size, sexual selection, and offspring viability in the Great Reed Warbler: Changing patterns in space and time. Behavioral Ecology 15:555563.

Garamszegi, L. Z., AND J. M. Avilés. 2005. Brood parasitism by Brown-headed Cowbirds and the expression of sexual characters in their hosts. Oecologia 143:167-177.

Grieef, P. M., AND S. G. SeAly. 2000. Simulated host activity does not attract parasitism by Brown-headed Cowbirds (Molothrus ater). Bird Behavior 13:69-78.

Grim, T. 2002. Why is mimicry in cuckoo eggs sometimes so poor? Journal of Avian Biology 33:302-305.

GRIM, T. 2007. Experimental evidence for chick discrimination without recognition in a brood parasite host. Proceedings of the Royal Society of London, Series B 274:373-381. 
GRIM, T. 2008. Are Blackcaps (Sylvia atricapilla) defending their nests also calling for help from their neighbours? Journal of Ornithology 149:169-180.

Grim, T., O. Kleven, and O. Mikulica. 2003. Nestling discrimination without recognition: A possible defence mechanism for hosts towards cuckoo parasitism? Proceedings of the Royal Society of London, Series B 270:S73-S75.

Hasselquist, D. 1998. Polygyny in Great Reed Warblers: A longterm study of factors contributing to male fitness. Ecology 79:2376-2390.

Hasselquist, D., And S. Bensch. 1991. Trade-off between mate guarding and mate attraction in the polygynous Great Reed Warbler. Behavioral Ecology and Sociobiology 28:187193.

Hasselquist, D., S. Bensch, and T. von Schantz. 1996. Correlation between male song repertoire, extra-pair paternity and offspring survival in the Great Reed Warbler. Nature 381:229232.

Hauber, M. E., C. Moskát, And M. BÁn. 2006. Experimental shift in hosts' acceptance threshold of inaccurate-mimic brood parasite eggs. Biology Letters 2:177-180.

KRÜGER, O. 2007. Cuckoos, cowbirds and hosts: Adaptations, tradeoffs and constraints. Philosophical Transactions of the Royal Society of London, Series B 362:1873-1886.

Lotem, A., H. NaKamura, AND A. Zahavi. 1992. Rejection of cuckoo eggs in relation to host age: A possible evolutionary equilibrium. Behavioral Ecology 3:128-132.

Lotem, A., H. Nakamura, and A. Zahavi. 1995. Constraints on egg discrimination and cuckoo-host co-evolution. Animal Behaviour 49:1185-1209.

McGregor, P. K., Ed. 2005. Animal Communication Networks. Cambridge University Press, Cambridge, United Kingdom.

McGregor, P. K., AND T. DAbelsteen. 1996. Communication networks. Pages 409-425 in Ecology and Evolution of Acoustic Comunication in Birds (D. E. Kroodsma and E. H. Miller, Eds.). Cornell University Press, Ithaca, New York.

McLaren, C. M., and S. G. Sealy. 2003. Factors influencing susceptibility of host nests to brood parasitism. Ethology Ecology \& Evolution 15:343-353.

Moskát, C., J. M. Avilés, M. Bán, R. Hargitai, and A. Zölei. 2008a. Experimental support for the use of egg uniformity in parasite egg discrimination by cuckoo hosts. Behavioral Ecology and Sociobiology 62:1885-1890.

Moskát, C., AND M. HonZA. 2000. Effect of nest and nest site characteristics on the risk of cuckoo Cuculus canorus parasitism in the Great Reed Warbler Acrocephalus arundinaceus. Ecography 23:335-341.

Moskát, C., ANd M. Honza. 2002. European cuckoo Cuculus canorus parasitism and host's rejection behaviour in a heavily parasitized Great Reed Warbler Acrocephalus arundinaceus population. Ibis 144:614-622.

Moskát, C., T. Székely, I. C. Cuthill, and T. Kisbenedek. 2008b. Hosts' responses to parasitic eggs: Which cues elicit hosts' egg discrimination? Ethology 114:186-194.

Palomino, J. J., M. Martin-Vivaldi, M. Soler, and J. J. Soler. 1998. Functional significance of nest size variation in the Rufous Bush Robin Cercotrichas galactotes. Ardea 86:177-185.

PAREJO, D., AND J. M. AvilÉs. 2007. Do avian brood parasites eavesdrop on heterospecific sexual signals revealing host quality? A review of the evidence. Animal Cognition 10:81-88.

Perrins, C. M. 1970. The timing of birds' breeding seasons. Ibis 112:242-255.

SAS InSTITUTE. 1996. SAS/STAT software changes and enhancements through release 6.11. SAS Institute, Cary, North Carolina.

Sih, A., A. Bell, And J. C. Johnson. 2004. Behavioral syndromes: An ecological and evolutionary overview. Trends in Ecology and Evolution 19:372-378.

Soler, J. J., J. J. Cuervo, A. P. Møller, And F. De Lope. 1998. Nest building is a sexually selected behaviour in the Barn Swallow. Animal Behaviour 56:1435-1442.

Soler, J. J., L. De Neve, J. G. Martínez, And M. Soler. 2001. Nest size affects clutch size and the start of incubation in magpies: An experimental study. Behavioral Ecology 12:301-307.

Soler, J. J., M. Soler, A. P. Møller, And J. G. Martínez. 1995. Does the Great Spotted Cuckoo choose magpie hosts according to their parenting ability? Behavioral Ecology and Sociobiology 36:201-206.

Szentirmai, I., J. Komdeur, AND T. SzéKely. 2005. What makes a nest-building male successful? Male behavior and female care in Penduline Tits. Behavioral Ecology 16:994-1000.

Török, J., C. Moskát, G. Michl, And P. PéCzely. 2004. Common Cuckoos (Cuculus canorus) lay eggs with larger yolk but not more testosterone than their Great Reed Warbler (Acrocephalus arundinaceus) hosts. Ethology Ecology \& Evolution 16:271-277.

Welbergen, J. A., AND N. B. DAVIES. 2008. Reed warblers discriminate cuckoos from sparrowhawks with graded alarm signals that attract mates and neighbours. Animal Behaviour 76:811-822.

Wyllie, I. 1981. The Cuckoo. Batsford, London.

Associate Editor: A. M. Dufty, Jr. 